\title{
Da música ao som: uma proposta para abordar o espaço
}

\author{
Thaís Amorim Aragão
}

Mestre em Planejamento Urbano e Regional (PROPUR-UFRGS, 2012).E-mail: thais.aragao@ufrgs.br

Recebido em 04/2012. Aceito para publicação em 12/2012.

Versão online publicada em 01/02/2013 (http://seer.ufrgs.br/paraonde)

\begin{abstract}
Resumo - Neste trabalho, é apresentada uma série de eventos relacionados a um particular trabalho com produção musical brasileira, que levou ao estudo do ambiente sonoro urbano. Tal estudo, em algum momento, acabou levando de volta à música brasileira. Procura-se refletir sobre como essa possibilidade metodológica se revelou, como foi assumida e que resultados gerou.
\end{abstract}

Palavras-Chave: Som. Música. Mercado. Identidade. Lugar.

\section{o que eu fazia e pensava quando me deparei com o objeto de pesquisa}

Em setembro de 2006, eu embarcava junto com uma comitiva de produtores culturais para Berlim, credenciados a participar da PopKomm, uma das maiores feiras europeias de negócios da música. Era ano de Copa, a Alemanha havia acabado de receber o mundial de futebol e o Brasil era o destaque da $18^{a}$. edição da feira, algo que até então nunca havia acontecido com um país fora do continente europeu - pelo menos assim estava sendo anunciada a façanha. No Mitte, um dos bairros em que se concentravam jovens dispostos a desfrutar ao ar livre as últimas semanas de clima aprazível e ensolarado antes que o inverno se pronunciasse, Ronaldinhos vestindo suas camisas oficiais da seleção canarinha podiam ser vistos em graffittis gigantescos nas paredes externas de edifícios cortesia da patrocinadora Nike. 0 verde e o amare- lo também estavam nos cartazes da feira espalhados em toda parte, o que fez com que a ideia de Brasil, que havia começado meses antes com o futebol, perdurasse na cidade com a presença de outra grande especialidade da nação sul-americana: a música.

Por trás de toda essa movimentação, havia uma série de planos de desenvolvimento interno e externo da economia brasileira, tendo como carrochefe o setor das chamadas indústrias criativas, mas com impacto em várias outras áreas ${ }^{1}$. 0 objetivo do governo brasileiro era intensificar relações comerciais - com a Alemanha, em particular - e reforçar a imagem do Brasil no exterior ${ }^{2}$. Havia sido inclusive criada a Marca Brasil, desenvolvida para ser usada em produtos brasileiros diversos, especialmente aqueles relacionados ao turismo, e construída a partir das ideias de "alegria", "sinuosidade / curva (da natureza, do caráter do povo)”, "luminosidade / brilho / exuberância", "encontro de culturas / mistura de raças", "moderno / competente ${ }^{3 "}$.

${ }^{1}$ Essa missão integrou o programa de intercâmbio cultural entre Brasil e Alemanha chamado Copa da Cultura. Sua organização esteve a cargo do Ministério da Cultura, em parceria com o Ministério das Relações Exteriores, o Ministério do Turismo, o Ministério do Esporte, a Sub-Secretaria da Comunicação da Presidência da República, a Agência de Promoção de Exportações e Investimentos (APEX) e a Embratur, do lado do Brasil; e das Casa das Culturas do Mundo e Instituto Goethe, com o apoio do Ministério das Relações Exteriores, do Ministério da Cultura e das Prefeituras de Berlim e Munique, por parte da Alemanha.

${ }^{2}$ O objetivo estava expresso no anúncio público da ação, no release de imprensa “Copa da Cultura: O Melhor da Produção Nacional na Alemanha": "Em 2006, futebol e arte estarão reunidos num programa de difusão da cultura brasileira no exterior". Disponível em: <http://www.copadacultura.gov.br/imprensa.html>. Acesso em: 02/04/2012.

${ }^{3}$ Esses termos foram reproduzidos do manual de uso da MARCA BRASIL em vigor em 2006, que se mantém no manual atualmente disponível em <http://www.turismo.gov.br/export/sites/default/turismo/multimidia /logotipos_marcas/galeria_arquivos_logotipos_marcas/m_brasil_nova_manual_1.pdf>.Acesso em: 02/04/2012. 
Aproveitando a porta oficialmente aberta, entramos como pequenos produtores (e havia outros maiores) em busca de público consumidor para o que desenvolvíamos em nossas bases: produtos culturais ligados à música. Estávamos ali, senão para disputar um mercado internacional incrivelmente competitivo, ao menos para chegar mais perto e tentar entender minimamente uma rede de relações na qual podíamos, ou não, nos inserir. Cheguei como coordenadora de um projeto de difusão da música do Ceará que tinha como desafio oferecer um panorama da produção do Estado naquele momento, ao mesmo tempo em que trazia o cartão de visitas de cada um dos 28 pontos da cadeia produtiva cearense da música englobados no recorte, definido grosso modo pela dinâmica de trabalho em produção cultural nos anos que antecederam a iniciativa. Neste recorte, havia empresas de produção, indústrias de mídias digitais (CD, DVD), um estúdio de gravação, um escritório de registro de obras, um escritório de design, uma empresa desenvolvedora de soluções para internet (websites, e-mail, sistemas de boletins eletrônicos etc), uma festa de periodicidade semanal, uma feira de negócios de música, uma associação que reunia agentes da produção fonográfica, o escritório do Sebrae Ceará - Serviço Brasileiro de Apoio às Micro e Pequenas Empresas ${ }^{4}$, além de dezesseis bandas, grupos, coletivos, artistas ou como possamos ainda vir a chamar os sujeitos que produziram a música registrada nas faixas da coletânea Ceará Original Soundtrack.

Minha pesquisa de mestrado em Planejamento Urbano e Regional pela Universidade Federal do Rio Grande do Sul foi bastante influenciada pela experiência proporcionada pelos eventos descritos, embora eles tenham sido apenas o início do processo que me levou ao trabalho que hoje desenvolvo. Para mim, particularmente, muito mais que encontrar mercados, a situação serviu para ampliar perguntas sobre a identidade brasileira e, especificamente, a cearense. Adianto que não me proponho aqui a abordar o que é chamado de marketing dos lugares, mas cabe fazer algumas considerações sobre como música e identidade nacional se articulam na globalização.
Michel Nicolau Netto, responsável pela organização do estande brasileiro na PopKomm e gestor do projeto Música do Brasil naquela ocasião, se ocupou dessa questão durante mestrado em Sociologia concluído na UNICAMP ${ }^{5}$. Curiosamente, ambos acabamos na academia, talvez uma espécie de divã onde nos deitamos para pensar no turbilhão de acontecimentos que se sucederam enquanto manipulávamos a própria noção de música brasileira num contexto mercadológico ou de relações internacionais. Vale trazer um pouco do raciocínio que ele desenvolveu sobre a missão, até porque meus sentimentos a esse respeito se aproximam em alguma medida do seu pensamento.

Considerando que "as identidades se tornam discursos que são usados para a valorização de um bem cultural" (NICOLAU NETTO, 2009, p. 190), ele concluiu que havia dois grupos de artistas entre aqueles cuja produção estava sendo apresentada em Berlim: um cujo discurso de apresentação tinha bastante marcada sua espacialidade, com "as origens temporais em registros remotos, os elementos mágicos, religiosos presentes e as atividades laborais fora do campo musical destacados" (idem, p. 189); e outro cujos artistas eram mostrados como "multilocalizados ou deslocalizados", com trabalhos bem recentes em que o uso de novas tecnologias era valorizado, e que eram especificamente profissionais da música.

Podemos pensar em dois tipos extremos de criadores. Um que, por falta de acúmulo de capital, necessita se fixar em uma identidade, sendo que sua imagem no mundo da música se torna esta própria identidade, impedindo-o de trocá-la. Ainda, por falta de capital este criador só pode buscar a identidade mais imediata, mais próxima a si e que, portanto, será territorializada. A esse chameramos de ator fixo. No outro extremo temos o criador cujo capital lhe permite não se fixar a qualquer identidade, pois não o necessita para se inserir no mercado cultural, mas que, quando ou se o fizer, será de forma controlada, estratégica e temporária, enquanto tiver interesse para tanto.

${ }^{4}$ Desvinculada da administração pública e transformada em instituição privada, sem fins lucrativos e de utilidade pública no ano de 1990, quando passou a ser mantida por repasses das maiores empresas do país, o Sebrae teve início junto com a Financiadora de Estudos e Projetos - FINEP em 1964. Com nomes diferentes, ambos formaram o Departamento de Operações Especiais do então Banco Nacional de Desenvolvimento Econômico (hoje também de desenvolvimento social: BNDES). 0 apoio gerencial às micro e pequenas empresas foi uma estratégia para combater um dos principais fatores que levavam à inadimplência nos contratos de financiamento firmados com o banco: a má gestão dos negócios. A entidade existe como instituição desde 1972, por iniciativa do BNDE e do Ministério do Planejamento.

${ }^{5}$ A pesquisa deu origem ao livro “Música brasileira e identidade nacional na mundialização”, publicado em 2009. 
Podemos conceituá-lo, então, de ator móvel. Assim, se do lado do primeiro criador temos todos os elementos da fixidez (a identidade é fixa e sua relação para com ela também o é), para o segundo temos todos os elementos da mobilidade. Em um tempo no qual a mobilidade se impõe como imperativo de sobrevivência é evidente que para o primeiro criador a vida no mercado cultural está fadada a não passar de um suspiro. Apenas sua imagem se manterá viva, como já se disse, mas de si alienada e apta a ser apropriada por outros criadores que poderão dela se aproveitar, mas nela não se fixarem. (idem, p. 193)

Quando fala em capital, se refere à noção de Pierre Bourdieu, considerando o capital econômico, o capital cultural e o capital social. "O baixo acúmulo de capitais leva o criador a se fixar em uma identidade restrita, geralmente não valorizada", afirma Nicolau Netto (idem, p. 195). Não valorizada por quem? Pelo que ele chama de "ouvidos dominantes", que exigem e determinam a adaptação de identidades por "atores móveis, que estão predominantemente espalhados por classes sociais privilegiadas em países economicamente centrais" (idem, p. 224). A troco de quê? De que entre no mercado internacional a música feita por brasileiros mas não todos.

Como disse, a experiência me rendeu mais perguntas e menos mercados do que esperava. As perguntas giravam basicamente em torno de por que fizemos o que fizemos, como fizemos, para que fizemos e o que aconteceu depois de tudo isso. Típico ciclo, ad eternum: planeja-se, executa-se, avaliase o projeto. E ainda estava remoendo essas questões quando, menos de seis meses depois, fomos convidados a fazer uma segunda compilação. Desta vez, a provocação nem mesmo surgiu do setor da música. Veio de produtores da moda - que, não por acaso, lidam com questões muito semelhantes relativas à articulação de identidades de lugar e da inserção de seu trabalho em mercados internos ou externos, cada um com suas próprias complexidades. Tomei minhas perguntas - e elas já carregavam parte das respostas - e partimos para a concepção do novo projeto.

A meu ver, a segunda compilação teve resultados muito mais expressivos - ainda que apenas nacionalmente - do que a primeira. Não porque as faixas, ou os artistas, ou o contexto musi- cal fossem muito diferentes do que no momento da primeira (ambas foram produzidas num período de apenas sete meses). Creio que nós - produtores, curadores, articuladores, fazedores ou como possamos ainda vir a ser chamados, no ato de selecionarmos, concebermos e apresentarmos tudo aquilo como uma ideia de conjunto para alguma finalidade específica - já estávamos pensando diferente essa tal música do Ceará, cuja ideia tínhamos andado anunciando tão longe de casa.

Diferentemente da primeira coletânea, não dispusemos mais a sequência das faixas a partir da música dita tradicional para a música dita moderna. Abrimos mão desse panorama de ilusória linearidade, patente de um caminho mental dentre vários possíveis para a leitura do todo. Pois se aqueles fonogramas foram produzidos no mesmo período, tratando-se portanto de produções contemporâneas, a tarefa de arranjá-los no tempo da mídia de suporte, sem sugerir aquele primeiro entendimento, deveria levar em consideração a possibilidade de uma escuta das faixas ao sabor do acaso. Assim, a sequência de Ceará Original Soundfashion tem um caráter aleatório - apenas aparente, uma vez que se tratou naturalmente de uma escolha.

Convidamos artistas visuais locais a escolher uma das faixas e a partir dela criar um cartão postal em que estivesse presente um cenário do estado $^{6}$ e uma peça de vestuário do acervo de um estilista de Fortaleza. Estávamos ainda trabalhando na lógica de um jogo de oferta e procura mas, na elaboração do que seria um novo cartão de visitas, multiplicamos as linguagens e os criadores em ação, o que fez com que se fragmentasse a tradução do que seriam as qualidades do lugar compartilhado que poderiam servir como vantagem diferencial a mercados aos quais possivemente iríamos nos conectar. Alguns desses mercados aceitam interagir com culturas não hegemônicas, desde que elas estejam de alguma forma agregadas a bens, que por sua vez possam atender às solicitações de consumidores em contextos diferentes daqueles que originaram tais bens, levando inevitavelmente a transformações ou perdas dos sentidos envolvidos na origem - caso possamos evocar uma origem.

Mas esse reprocessamento de identidades iniciado pela segunda compilação serviu mais ao consumo interno. Nenhuma feira internacional de música viu circular o resultado desse encontro de criadores. A experiência levou a um processo em que todos os que ali se serviam da ideia de Ceará e a rearticulavam puderam não apenas reconstrui-la para fora, mas reinterpretá-la também para uso

${ }^{6}$ Nesta época eu estava distante da Geografia e nem sabia o quanto a palavra cenário, muito usada nas artes, estava próxima do conceito de paisagem. 
próprio, como um exercício de manipulação coletiva de imagens do lugar a partir do qual nos colocamos no mundo, produzidas, selecionadas e mescladas pelo próprio grupo. Interessante o comentário de um leitor do texto "O Novo Ecletismo Cearense", que o antropólogo Hermano Vianna publicou em agosto de 2007, no site colaborativo Overmundo:
"Acho legal ver como na prática neguinho é mais bem resolvido com as questões de identidade, diálogo entre mídias e estilos, do que na teoria. As coisas simplesmente acontecem independente da teorização e o rancor de acadêmicos e analistas. Isso é lindo!" (Joao Xavi, São João de Meriti, RJ, 25/8/2007, às 14:19).

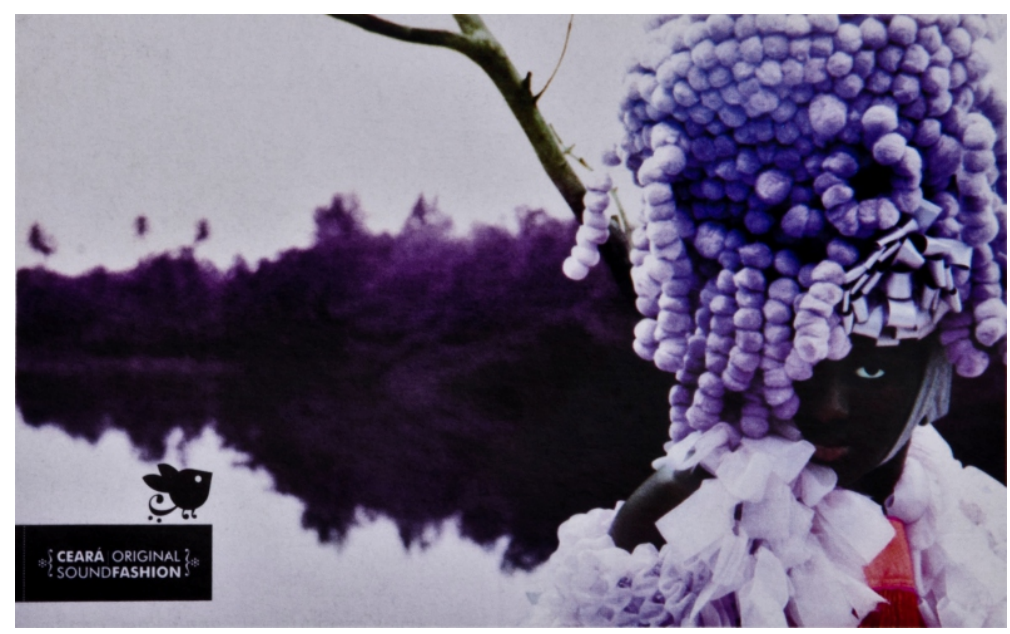

Imagem 1. Cartão postal produzido para a faixa "O pinto de peitos", do Cidadão Instigado. Fotografia de Patrícia Araújo, direção de arte de Charles W, figurino de Mark Greiner, modelo Délcia Janine. Cenário: Rio Cocó, Sapiranga, Fortaleza-CE.

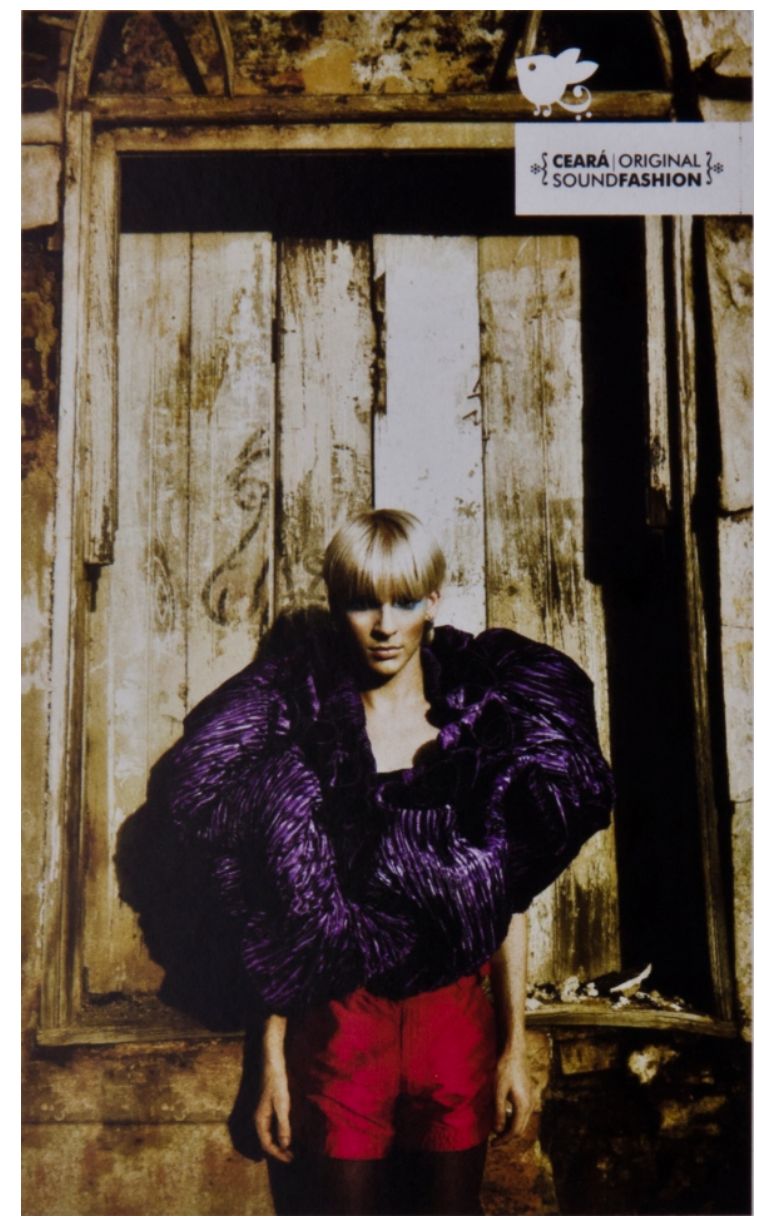

Imagem 2. Cartão postal para a faixa "Raio de Fogo", do Montage. Fotografia de Filipe Acácio, modelo Daniel Peixoto (vocalista do duo), figurino de Mark Greiner. Cenário: Centro Histórico, Aracati-CE. 


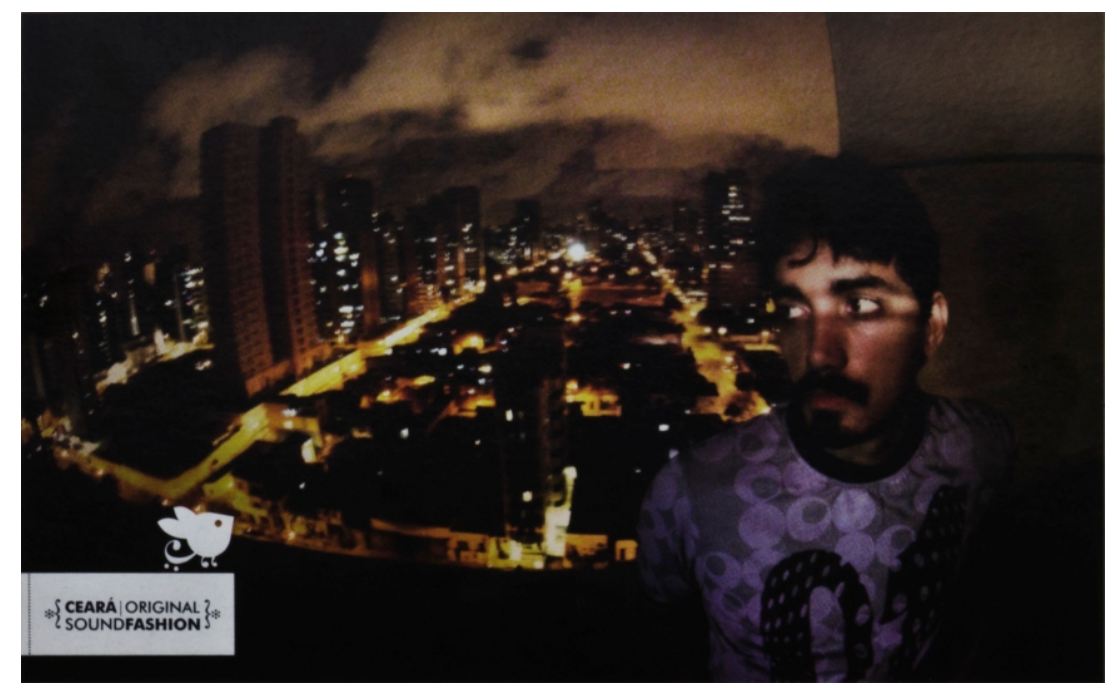

Imagem 3. Cartão postal para a faixa "Inóspito", de George Belasco \& 0 Cão Andaluz. Fotografia de Lia de Paula, modelo George Belasco, figurino de Mark Greiner. Cenário: Meireles, Fortaleza-CE.

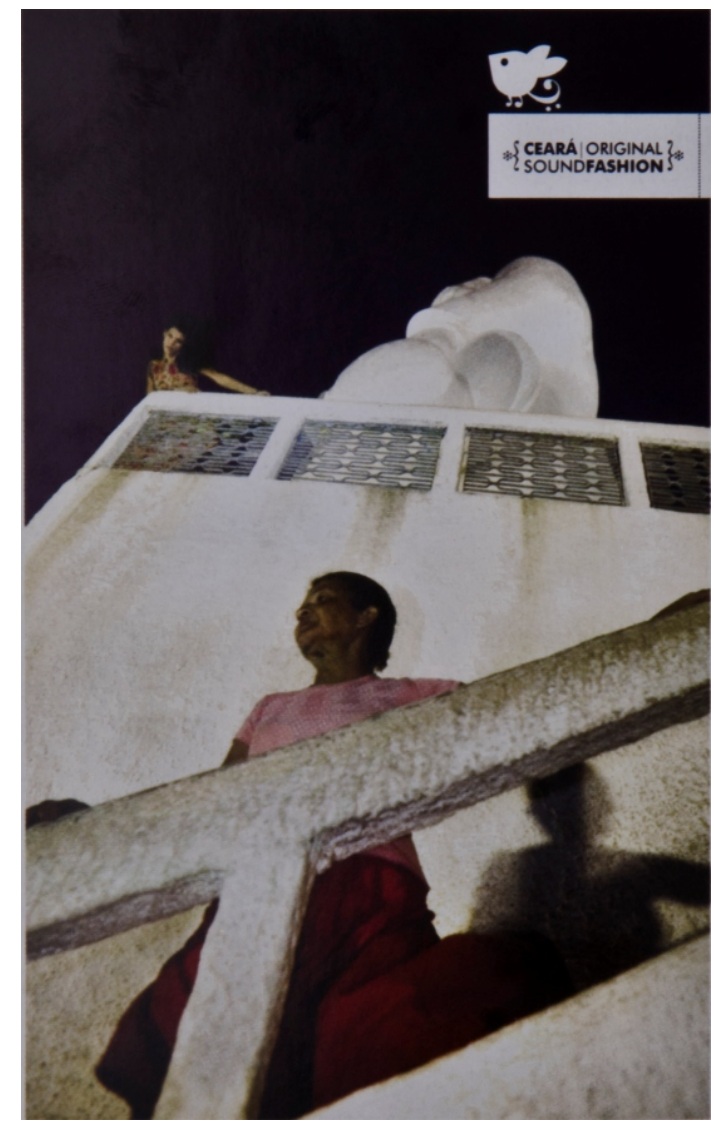

Imagem 4. Cartão postal para a faixa "Ida do Padim pra Céu”, de domínio público, cantada por Dona Maria do Horto e arranjada por Di Freitas. Fotografia de Dada Petrole, modelos Dona Maria e Hívina Princy, figurino de Mark Greiner. Cenário: Horto, Juazeiro do Norte-CE.

Teria sido bom constatar que o espetáculo virou festa, mas isso ficará no plano do desejo e da expectativa. Pois eu mesma mudei um pouco de curso. A experiência com o mercado globalizado parecia um caminho possível, mas a música em si mostrava outras direções. Ainda em 2006, partici- pei ativamente do Fórum de Música Experimental que aconteceu em Fortaleza de forma tão intensa quanto abreviada - menos de um ano - e do minicurso ministrado por Marisa Fonterrada no III Festival de Música de Ibiapaba. Nessa viagem a Viçosa do Ceará para uma semana de estudos, levei na 
bagagem "A afinação do mundo", livro que Fonterrada, professora do Programa de Pós-graduação em Música do Instituto de Artes da UNESP, havia traduzido e no qual o compositor canadense Murray Schaffer destrinchou sua ideia de paisagem sonora.

Logo depois que Ceará Original Soundfashion foi lançada, no início de 2007, acabei vindo passar alguns meses em Porto Alegre, onde fiz um curso de extensão com o professor Eloy Fritsch no Centro de Música Eletrônica da UFRGS e realizei passagem pelo Coletivo Antena, que agregou em torno da música de ruído artistas como Guilherme Darisbo, Rodrigo Avellar Muniagurria e Cristiano Rosa. Em paralelo, portanto, à busca do que viria a ser uma identidade cearense por meio da música, também havia explorações sobre o que concebemos como música e as relações com ruído, barulho, silêncio.

A música [...] é a organização do ruído (ATTALI, 1996, p. 4). É a elaboração de sentido a partir da seleção, produção e socialização de sons, que cada cultura vai realizar à sua maneira. Como exemplo de sistematização, existem diversos registros de escalas musicais distintas, utilizadas em diferentes lugares do mundo, e algumas sociedades chegaram até mesmo a desenvolver seus próprios sistemas de escrita (notação) musical. [...] "O som do mundo é ruído", diz José Miguel Wisnik. (ARAGÃO, 2009)

O livro Noise: The Political Economy of Music, do francês Jacques Attali, ajudaria a unir as duas pontas do debate, e este era o livro que lia na viagem de volta a Fortaleza. Meus planos na cidade eram concluir a especialização em Comunicação e Cultura e iniciar a edição de um documentário. Foi quando-e onde-algo curioso aconteceu.

\section{Reencontro}

As viagens haviam desacelerado minha rotina na capital cearense. Havia muito menos atividades programadas para acontecer do que antes, quando um projeto imediatamente se sucedia a outro, e vários deles eram realizados ao mesmo tempo, em etapas diferentes. Antes, o cotidiano era marcado por numerosas reuniões e saídas para diversas tarefas, com muito uso de carro para chegar a vários pontos da cidade, interligando a agenda. Estar desconectada desse tipo de trabalho resultou em mais tempo para os estudos, aos quais dedicava tardes inteiras, no interior de um quarto, em casa. Estava provavelmente aí lendo ou escrevendo quando, de repente, comecei a escutar um som familiar ao longe, na vizinhança. Inicialmente baixo, vinha gradativamente aumentando em intensidade e logo me dei conta de que era o vendedor de chegadinho que estava se aproximando.

Nos últimos três anos tenho repetidamente explicado o que é chegadinho, sempre com um certo de receio de não parecer repetitiva, pois trata-se de algo muito simples: chegadinho é um biscoito doce extremamente fino, em forma de cone, vendido em tambores cilíndricos por vendedores que os carregam às costas pendurados pelos ombros, enquanto tocam um triângulo pelas ruas. 0 som que esses ambulantes emitem, no entanto, traz uma certa nostalgia a muitos habitantes da cidade. Ao escutar aquele tilintar, muitos fortalezenses são levados a lembranças de infância e a uma ideia de cidade que se localizaria no passado. Trata-se de uma experiência forte vivida durante a meninice e em certa medida compartilhada por alguns habitantes, cuja potência pode ser explicada pelos primeiros encontros dos pequenos citadinos com a efervescência de uma vida urbana misteriosa, que se encontra para além do espaço doméstico. É como se o som do triângulo do vendedor de chegadinho anunciasse que esse turbilhão de acontecimentos está passando à sua porta, e que é possível interrompê-lo, interagir com ele, bastando para isso chamar o ambulante.

No instante em que, de volta a Fortaleza, pude ouvir novamente aquele tilintar, encontrei o que podia ser uma música do Ceará que não havia sido registrada, nem mesmo vislumbrada, nas coletâneas musicais em que havíamos assumido tal recorte espacial: os sons de nossas ruas. Estava convencida de que havia algo especial escondido ali; algo que um certo distanciamento de ordem espaço-temporal havia me possibilitado entrever ou entreouvir. Essa suspeita me levou a estudar a cidade, o espaço urbano, o lugar, o território, mas sempre partindo do ambiente sonoro, que se mostrou para mim um campo mais amplo e menos dado a amarras, o que nos favorece especialmente se nos interessamos por identidade na medida em que nos interessamos por cultura, num sentido mais antropológico.

Os resultados da pesquisa de mestrado já foram colhidos e muito em breve serão apresentados na defesa da dissertação. Posso adiantar que investigar a prática relacionada ao episódio narrado me levou a revelações sobre como um som aparentemente banal, que parece quase esquecido pelos cantos do cotidiano de nossas cidades, reverberou de forma quase inaudita em nossas cons- 
ciências e costumes. E mais: se inscreveu profundamente na música popular brasileira do século XX, após sucessivos rebatimentos ao longo de um complexo processo de formação de nossas próprias identidades.

Descobri que o som que os vendedores fazem soar pelas ruas está ligado a costumes anteriores à nossa experiência com a indústria fonográfica, que tem pouco mais de cem anos e que sido catalizadora de novas e poderosas ebulições culturais. De alguma forma, aqueles prosaicos sons das ruas entraram nessas novas etapas de transformação. Além disso, o som do triângulo daqueles ambulantes relaciona diversos lugares no território brasileiro, particularmente abarcados pelas linhas imaginárias que contém o que hoje chamamos de Nordeste, além de alguns pontos no que é a região Norte. Ainda conecta esses espaços do Brasil à Península Ibérica e a outras cidades iberoamericanas. Tais descobertas abrem novas possibilidades de pesquisa e ajudam a consolidar os estudos dos ambientes sonoros como uma rica abordagem sobre os espaços.

Voltar ao som quando buscava entender a música se mostrou um caminho que pode ser mais amplamente explorado. Se a música já é uma organização do ruído, e se a própria concepção do que é ruído em nossas sociedades também repousa sobre convenções - ou seja, sobre processos culturais -, talvez os sons do ambiente podem ser um ponto de fuga onde nos desconectamos de forças mais prementes, como supostas necessidades ou contigências presentes que nos levam a pensar a música de um determinado local a partir de um campo em que identidades são convertidas em capital e negociadas desigualmente (podendo ser nós os que perdem nessa operação). Por fim, o estu- do do som, anterior mas não desconectado da música, pode nos fornecer algumas condições favoráveis à tarefa de transpor a experiência imediata e superar o que Bacherlard (1996) chama de obstáculos epistemológicos, que nos impedem de chegar ao conhecimento. Por vezes, temos que estar prontos para alterar até mesmo a forma como conhecer, a fim de chegar a outra etapa da busca que empreendemos pelo saber.

\section{Referências}

ARAGÃO, Thaís Amorim. Chegadinho: Doce paisagem sonora. In: XIII ENAnpur - Encontro Nacional da ANPUR, 2009, Florianópolis-SC. Planejamento e Gestão do Território... Florianópolis: Universidade Federal de Santa Catarina, 2009.

BACHELARD, Gaston. A formação do espírito científico. Rio de Janeiro: Contraponto, 1996.

NICOLAU NETTO, Michel. Música brasileira e identidade nacional na mundialização. São Paulo: Anablume; Faspesp, 2009.

SCHAFER, R.Murray. A afinação do mundo. São Paulo: Editora Unesp, 2001.

VIANNA, Hermano. O Novo Ecletismo Cearense. Overmundo, Rio de Janeiro, 25 ago. 2007. Disponível em <http://www.overmundo.com.br/overblog /o-novo-ecletismo-cearense>. Acesso em 02 abr. 2012.

WISNIK, J.M. O Som e o Sentido - Uma outra história das músicas. São Paulo: Companhia das Letras, 2006.

\title{
From music to sound: a proposal to study space
}

\begin{abstract}
This work presents a serie of events related with Brazilian musical business that lead to the study of urban acoustic environments - such efforts, afterwards, brough the investigation back to Brazilian music. Some considerations about the methodological possibility that emerged from this experience, how it was assumed and what resulted from it are in discussion.
\end{abstract}

Keywords: Sound. Music. Business. Identity. Place.

\section{De la música al sonido:una propuesta para abordar el espacio}

\footnotetext{
Resumen - En este trabajo, es narrada una serie de eventos relacionados a un particular trabajo de producción musical brasilero que condujo al estudio del paisaje sonoro urbano. Tal estudio, en algún momento, condujo de vuelta a la música brasilera. Asi, se pretende reflexionar sobre cómo esta posibilidad metodológica se reveló, cómo fue asumida y que resultados ha generado.

Palabras clave: Sonido. Música. Mercado. Identidad. Lugar.
} 